\title{
Análise qualitativa: teoria, passos e fidedignidade
}

\author{
Qualitative analysis: theory, steps and reliability
}

Maria Cecília de Souza Minayo ${ }^{1}$

${ }^{1}$ Centro Latino-Americano de Estudos de Violência e Saúde (Claves), Escola Nacional de Saúde Pública (Ensp), Fundação Oswaldo Cruz. Av. Brasil 4036/700, Manguinhos. 21040-361 Rio de Janeiro RJ. maminayo@terra.com.br
Abstract This essay seeks to conduct in-depth analysis of qualitative research, based on benchmark authors and the author's own experience. The hypothesis is that in order for an analysis to be considered reliable, it needs to be based on structuring terms of qualitative research, namely the verbs 'comprehend' and 'interpret', and the nouns 'experience', 'common sense' and 'social action'. The 10 steps begin with the construction of the scientific object by its inclusion on the national and international agenda; the development of tools that make the theoretical concepts tangible; conducting field work that involves the researcher empathetically with the participants in the use of various techniques and approaches, making it possible to build relationships, observations and a narrative with perspective. Finally, the author deals with the analysis proper, showing how the object, which has already been studied in all the previous steps, should become a second-order construct, in which the logic of the actors in their diversity and not merely their speech predominates. The final report must be a theoretic, contextual, concise and clear narrative.

Key words Qualitative analysis, Qualitative research, Comprehension, Interpretation, Dialectics
Resumo Neste ensaio busca-se aprofundar a reflexão sobre o processo de análise na pesquisa qualitativa a partir de autores referenciais e da experiência da própria autora. O texto está organizado em forma de decálogo por meio do qual é tratado o tema processualmente. A hipótese é de que uma análise para ser fidedigna precisa conter os termos estruturantes da investigação qualitativa que são os verbos: compreender e interpretar; e os substantivos: experiência, vivência, senso comum e ação social. A seguir a proposta avança por 10 passos que se iniciam na construção científica do objeto pela sua colocação no âmbito do conhecimento nacional e internacional, na elaboração de instrumentos que tornem concretos os conceitos teóricos, na execução de um trabalho de campo que envolva empaticamente o investigador no uso de vários tipos de técnicas e abordagens, tornando-o um construtor de relações, de observações e de uma narrativa em perspectiva. Por fim, a autora trata da análise propriamente dita, mostrando como o objeto, que já vem pensado em todas as etapas anteriores, deve se tornar um construto de segunda ordem, em que predomine a lógica dos atores em sua diversidade e não apenas as suas falas, dentro de uma narrativa teorizada, contextualizada, concisa e clara.

Palavras-chave Análise qualitativa, Pesquisa qualitativa, Compreender, Interpretar, Dialetizar 
Introdução e estratégia de construção do texto

Neste artigo apresento uma reflexão sobre o processo de análise qualitativa de estudos com base empírica. O texto tem duas fontes de inspiração: a primeira são os vários autores com os quais venho dialogando durante mais de 25 anos. A segunda é minha própria vivência como investigadora, orientadora de teses e de dissertações e como professora na área de saúde coletiva.

Começando pela minha experiência, ressalto que de todas as demandas que recebo de estudantes e colegas, a mais recorrente diz respeito a como fazer análise do material qualitativo. É como se todas as outras fases da pesquisa, a preparação do projeto e o trabalho de campo configurassem etapas muito simples e fáceis de serem resolvidas, em contraposição às dificuldades de como tratar os achados empíricos e documentais. Essa preocupação procede, pois é diferente dos estudos quantitativos em que os dados colhidos de forma padronizada e tratados com técnicas de análise sofisticadas oferecem ao pesquisador certa segurança quanto à fidedignidade de seu estudo. Uma segurança que a rigor deveria ser questionada ${ }^{1}$. No caso da pesquisa qualitativa, muitos outros problemas - que na verdade são parte de sua própria contingência e condição - dificultam saber de antemão se as informações recolhidas e as análises elaboradas poderiam ser consideradas válidas e suficientes.

Divido este trabalho em duas partes. Na primeira, mostro que uma boa análise começa com a compreensão e a internalização dos termos filosóficos e epistemológicos que fundamentam a investigação e, do ponto de vista prático, desde quando iniciamos a definição do objeto. Na segunda parte, discorrei sobre o processo da análise propriamente dito.

Fazer ciência é trabalhar simultaneamente com teoria, método e técnicas, numa perspectiva em que esse tripé se condicione mutuamente: $\mathrm{o}$ modo de fazer depende do que o objeto deman$\mathrm{da}$, e a resposta ao objeto depende das perguntas, dos instrumentos e das estratégias utilizadas na coleta dos dados. À trilogia acrescento sempre que a qualidade de uma análise depende também da arte, da experiência e da capacidade de aprofundamento do investigador que dá o tom e o tempero do trabalho que elabora.

Tento apontar algumas questões cruciais que oferecem as balizas da objetivação $0^{2,3}$ e do caráter incompleto, provisório ${ }^{4-6}$ e aproximativo do conhecimento ${ }^{7}$.

\section{Discussão}

As premissas para a discussão da análise qualitativa estão apresentadas em forma de decálogo, na busca de facilitar a compreensão para os que buscam se familiarizar com a abordagem qualitativa.

Primeiro: Conhecer os termos estruturantes das pesquisas qualitativas. Sua matéria prima é composta por um conjunto de substantivos cujos sentidos se complementam: experiência, vivência, senso comum e ação. E o movimento que informa qualquer abordagem ou análise se baseia em três verbos: compreender, interpretar e dialetizar ${ }^{8}$.

O termo experiência utilizado historicamente por Heidegger ${ }^{9}$, diz respeito ao que o ser humano apreende no lugar que ocupa no mundo e nas ações que realiza. O sentido da experiência é a compreensão: o ser humano compreende a si mesmo e ao seu significado no mundo da vida9. Por ser constitutiva da existência humana, a experiência alimenta a reflexão e se expressa na linguagem. Mas, a linguagem não traz a experiência pura, pois vem organizada pelo sujeito por meio da reflexão e da interpretação num movimento em que o narrado e o vivido por si estão entranhados na e pela cultura, precedendo à narrativa e ao narrador $^{10}$. Já a vivência é produto da reflexão pessoal sobre a experiência. Embora a experiência possa ser a mesma para vários indivíduos (irmãos numa mesma família, pessoas que presenciam um fato, por exemplo) a vivência de cada um sobre o mesmo episódio é única e depende de sua personalidade, de sua biografia e de sua participação na história. Embora pessoal, toda vivência tem como suporte os ingredientes do coletivo em que o sujeito vive e as condições em que ela ocorre. $\mathrm{O}$ senso comum pode ser definido como um corpo de conhecimentos provenientes das experiências e das vivências que orientam o ser humano nas várias ações e situações de sua vida ${ }^{6,9-11}$. Ele se constitui de opiniões, valores, crenças e modos de pensar, sentir, relacionar e agir. O senso comum se expressa na linguagem, nas atitudes e nas condutas e é a base do entendimento humano. Dado o seu caráter de expressão das experiências e vivências, o senso comum é o chão dos estudos qualitativos. A ação (humana e social) pode ser definida como o exercício dos indivíduos, dos grupos e das instituições para construir suas vidas e os artefatos culturais, a partir das condições que eles encontram na realidade. $O$ conceito de ação está vinculado à noção de liberdade para agir e transformar o mundo que, para Heidegger ${ }^{4}$, não constitui um lugar e sim um complexo formado pela significação das experiências que fazem do ser humano um ser histórico. 
O verbo principal da análise qualitativa é compreender. Compreender é exercer a capacidade de colocar-se no lugar do outro, tendo em vista que, como seres humanos, temos condições de exercitar esse entendimento ${ }^{6}$. Para compreender, é preciso levar em conta a singularidade do indivíduo, porque sua subjetividade é uma manifestação do viver total. Mas também é preciso saber que a experiência e a vivência de uma pessoa ocorrem no âmbito da história coletiva e são contextualizadas e envolvidas pela cultura do grupo em que ela se insere. Toda compreensão é parcial e inacabada, tanto a do nosso entrevistado, que tem um entendimento contingente e incompleto de sua vida e de seu mundo, como a dos pesquisadores, pois também somos limitados no que compreendemos e interpretamos. Ao buscar compreender é preciso exercitar também o entendimento das contradições: o ser que compreende, compreende na ação e na linguagem e ambas têm como características serem conflituosas e contraditórias pelos efeitos do poder, das relações sociais de produção, das desigualdades sociais e dos interes$\operatorname{ses}^{12}$. Interpretar é um ato contínuo que sucede à compreensão e também está presente nela: toda compreensão guarda em si uma possibilidade de interpretação, isto é, de apropriação do que se compreende. A interpretação se funda existencialmente na compreensão e não vice-versa, pois interpretar é elaborar as possibilidades projetadas pelo que é compreendido ${ }^{6,9}$.

Segundo - Definir o objeto sob a forma de uma pergunta ou de uma sentença problematizadora e teorizá-lo. A indagação inicial norteia o investigador durante todo o percurso de seu trabalho. Sua reflexão analítica, neste momento, orienta-se para o delineamento adequado do objeto no tempo e no espaço: que não deve ser tão amplo que permita apenas uma visão superficial e nem tão restrito que dificulte a compreensão de suas interconexões. A definição de um objeto não reside na indagação em si, mas no seu esclarecimento e contextualização por meio da teorização que o torna um fato científico construído. É óbvio que a clareza sobre o objeto - que nunca será total e definitiva - só se alcança ao final de uma pesquisa. Qualquer investigação nada mais é do que a busca de responder à indagação inicial. Como nos lembra Pascal ${ }^{13}$, a conclusão de uma obra já deve estar latente em sua formulação, pois todas as coisas são causadas e causadoras.

Para tornar o objeto um construto científico é preciso investir no conhecimento nacional e internacional acumulado, dialogando com ele ou em torno dele, caso não haja estudos sobre o mesmo assunto, como ocorre nas investigações exploratórias. Feita a análise das fontes de pesquisa, o investigador deve escolher o marco teórico que vai adotar, detalhando os conceitos, as categorias e as noções que fazem sentido para sua pesquisa. Este é o momento também de colocar de forma mais fundamentada as hipóteses ou os pressupostos que já existiam como intuição nas indagações iniciais.

Terceiro - Delinear as estratégias de campo. É preciso ter em mente que os instrumentos operacionais também contêm bases teóricas: são constituídos de sentenças (no caso dos roteiros) ou orientações (no caso da observação de campo) que devem guardar estreita relação com o marco teórico, sendo cada um desses elementos um tipo de conceito operativo pensado na teorização inicial.

Quarto - Dirigir-se informalmente ao cenário de pesquisa, buscando observar os processos que nele ocorrem. É preciso ir a campo sem pretensões formais e ampliar o grau de segurança em relação à abordagem do objeto, inclusive, se possível, realizar algumas entrevistas abertas, promover o redesenho de hipóteses, pressupostos e instrumentos, buscando uma sintonia fina entre o quadro teórico e os primeiros influxos da realidade. O olhar analítico deve acompanhar todo o percurso de aproximação do campo.

Quinto - Ir a campo munido de teoria e hipóteses, mas aberto para questioná-las. É preciso imergir na realidade empírica na busca de informações previstas ou não previstas no roteiro inicial. Conforme ensina Malinowski ${ }^{14}$ em seu clássico trabalho sobre os princípios da abordagem antropológica: é fundamental ter todo o material teórico elaborado, todos os instrumentos operacionais prontos e à disposição, como se o êxito da investigação dependesse somente deles. Mas é também crucial estar tão atento e tão aberto às novidades do campo que, caso seja preciso, o investigador abra mão de suas certezas a favor dos influxos da realidade. Lembra Lévy-Strauss ${ }^{15}$ :

"O trabalho de campo é mãe e nutriz de toda dúvida (...) antropológica que consiste em se saber que nada se sabe, mas, também em expor o que se pensava saber, às pessoas que [no campo] podem contradizer [nossas verdades mais caras]".

Num trabalho de campo profícuo, o pesquisador vai construindo um relato composto por depoimentos pessoais e visões subjetivas dos interlocutores, em que as falas de uns se acrescentam às dos outros e se compõem com ou se contrapõem às observações. É muito gratificante quando ele consegue tecer uma história ou uma narrativa coletiva, da qual ressaltam vivências e experiências com suas riquezas e contradições. Já 
nesse momento, o pesquisador pode articular as informações que recebe como num quebra-cabeças, e para enriquecê-las, buscar novos interlocutores e fazer novas observações. É preciso ressaltar que um relato coletivo não significa um conto homogêneo e, sim, uma história em que os diversos interesses e as várias visões tenham lugar e possibilidade de expressão. Bertaux ${ }^{16}$ considera que um bom trabalho de campo é ao mesmo tempo a "construção de uma representação do objeto socioantropológico". Em resumo, o trabalho de campo não é um exercício de contemplação. Tanto na observação como na interlocução com os atores o investigador é um ator ativo, que indaga, que interpreta, e que desenvolve um olhar crítico.

Sexto - Ordenar e organizar o material secundário e o material empírico e impregnar-se das informações e observações de campo. É preciso investir na compreensão do material trazido do campo, dando-lhe valor, ênfase, espaço e tempo. Tendo em vista que a análise do material qualitativo se apóia nos verbos e substantivos citados no primeiro ponto do decálogo, qualquer tentativa de realizá-la apenas tecnicamente empobrece os resultados.

A ordenação constitui um trabalho organizativo: (1) dos textos teóricos e referências que balizaram o projeto e agora precisam ser complementadas; (2) do material de observação, que geralmente está contido no diário de campo, fonte legítima de informação para compor a análise; (3) dos documentos geográficos, históricos, estatísticos e institucionais que porventura existam, que foram pesquisados e que devem ajudar na contextualização do objeto; (4) das entrevistas, resultados de grupos focais e de outras fontes primárias (que devem ter sido desgravadas caso a interlocução tenha sido mediadas por gravações). Os elementos citados nos itens 1,2,3 são contextuais. Os do item 4 dizem respeito ao conteúdo das falas e das observações que a partir de então devem ter prioridade numa leitura atenta, reiterativa e cheia de perguntas. A esse movimento costumo chamar de "impregnação" ou "saturação".

Sétimo - Construir a tipificação do material recolhido no campo e fazer a transição entre a empiria e a elaboração teórica. O processo de tipificação é mais denso e intenso que o exercício de ordenação, mas tem a mesma finalidade: apropriação da riqueza de informações do campo, tentando, na medida do possível, não "contaminálo" por meio de uma interpretação precipitada. É preciso esclarecer que não existe uma mente vazia de dados anteriores ou uma cabeça isenta de teorias e ideologia. $\mathrm{O}$ esforço compreensivo tem o sentido de valorizar ao máximo os achados do campo. Para isso é importante: (1) organizar os relatos e os dados de observação em determinada ordem. Por exemplo, caso a pesquisa empírica tenha sido feita com grupos diferenciados por classe social, por idade, por sexo, por religião, por épocas históricas diferentes (todas essas divisões são aqui hipotéticas), vários subconjuntos devem ser criados, visando a uma leitura das homogeneidades e das diferenciações para que seja possível fazer comparações entre os vários subconjuntos. (2) As leituras horizontais de impregnação dão lugar a uma elaboração transversal do conjunto ou de cada subconjunto do material empírico, com uma intenção específica: recortar cada item do texto, conforme foram apresentados pelos entrevistados ${ }^{10}$. Todo esse esforço de recorte e colagem pode ser organizado tecnicamente em subconjuntos ou gavetas, separados por assuntos, constituindo já a primeira forma de classificação do material; (3) em seguida, o pesquisador dá um passo a mais na compreensão das estruturas de relevância apresentadas pelos entrevistados. O material contido nas muitas gavetas deve passar por uma nova leitura e organização para que seja rearrumado em quatro ou cinco tópicos que os entrevistados destacaram, sobretudo, por meio da reiteração. O esforço de síntese diminui o número de subconjuntos, mas não despreza a riqueza de informações. Apenas a reclassifica, enfatizando quais são as estruturas de relevância apontadas no estudo de campo. Dentro de cada tópico, as questões devem ser tratadas em sua homogeneidade e em suas diferenciações internas. $\mathrm{O}$ movimento classificatório que privilegia o sentido do material de campo não deve buscar nele uma verdade essencialista, mas o significado que os entrevistados expressam.

A esse momento fundamental em que pouco a pouco o pesquisador chega ao sentido das falas e de sua contextualização empírica denomino lógica interna dos atores, do grupo, ou do segmento. No momento em que compreender o sentido do que lhe foi relatado e do que observou no campo, o pesquisador não necessita mais estar colado às falas: seu aprisionamento a elas é uma das maiores fraquezas de quem faz análise qualitativa, pois significa que o investigador não foi capaz de ultrapassar o nível descritivo do seu material empírico. Como nos lembra Canguil$\operatorname{lem}^{17}$ : A verdade só ganha sentido ao fim de uma polêmica. Assim não poderia haver verdade primeira. Só há erros primeiros. A evidência primeira nunca é uma verdade fundamental.

Oitavo - Exercitar a interpretação de segunda ordem. A compreensão propiciada pela leitu- 
ra atenta, aprofundada e impregnante que deu origem às categorias empíricas ou unidades de sentido, nesse momento, deve merecer um novo processo de teorização. Pode ocorrer que as referências teóricas que constituíram balizas fundamentais para o início da investigação não sejam suficientes para contemplar a interpretação dos achados de campo. Em forma de tópicos, no caso de um artigo, ou de capítulos (no caso de elaboração de um livro) cada uma das unidades de sentido deve então merecer uma leitura de referências nacionais e internacionais, de forma a colocar o material classificado, no contexto das questões nacionais e internacionais que ele suscita. E igualmente, é importante enriquecer todo o conjunto de falas e observações, com elementos históricos e contextuais: para que de sua "aldeia" o pesquisador converse com o mundo e sobre o mundo, de forma compreensiva e crítica.

A interpretação nunca será a última palavra sobre o objeto estudado, pois o sentido de uma mensagem ou de uma realidade está sempre aberto em várias direções. No entanto, quando bem conduzida, ela deve ser fiel ao campo de tal maneira que caso os entrevistados estivessem presentes, compartilhariam os resultados da análise. Gadamer ${ }^{6}$ acrescenta, recuperando o pensamento de vários autores como Dilthey ${ }^{18} \mathrm{e}$ Schleiermarcher ${ }^{19}$, que a interpretação deve ir além dos entrevistados e surpreendê-los, pois quando eles deram seus depoimentos, não tinham consciência de tudo o que seria possível compreender, a partir de suas falas, sobre seu tempo, seus contemporâneos e sobre a sociedade em que vivem.

Nono - produzir um texto ao mesmo tempo fiel aos achados do campo, contextualizado e accessível. A conclusão de uma análise qualitativa deve apresentar um texto capaz de transmitir informações concisas, coerentes e, o mais possível, fidedignas. Pois, o relato final da pesquisa configura uma síntese na qual o objeto de estudo reveste, impregna e entranha todo o texto. O contexto, as determinações mais próximas e as mais abstratas, nessa etapa do "concreto pensado" devem emanar do objeto e não ao contrário. Portanto, consideramos um trabalho incompleto ou pobre o que apenas descreve o que encontrou no campo. Mas a compreensão e a interpretação em seu formato final, também assinalam um momento na práxis do pesquisador. Por isso, nunca será uma obra acabada e suas conclusões devem se abrir para novas indagações. Na sua exposição, é importante que o autor inclua suas condições e suas dificuldades de interpretação, pois elas fazem parte da objetivação da realidade e de sua própria objetivação $0^{21}$.
Décimo - Assegurar os critérios de fidedignidade e de validade. Popper ${ }^{22}$ nos lembra que a objetividade é uma questão social dos cientistas, envolvendo a crítica recíproca, e "a divisão hostil-amistosa de seu trabalho, sua cooperação ou também sua competição". Mas os critérios de verificação devem ser assegurados, assim como um certo apego do cientista a sua proposta e a seus métodos, diz Popper, pois "se nos sujeitarmos à crítica com demasiada facilidade, nunca descobriremos onde está a verdadeira força de nossas teorias"22. No sentido de salvaguardar a fidedignidade, sugerimos alguns passos: (1) O primeiro de todos é aquele que guia universalmente toda pesquisa científica: teoria, método e técnicas adequados, descritos e avaliáveis por qualquer outro investigador. (2) Por exigir presença, envolvimento pessoal e interação do pesquisador em todo o processo, uma boa análise qualitativa deve explicitar suas ações no campo, assim como seus interesses e dificuldades na construção do objeto. Existem ainda alguns cuidados possíveis de serem realizados durante o processo de realização da investigação que lhe asseguram maior grau de validade: (3) a triangulação interna à própria abordagem ${ }^{23}$, que consiste em olhar o objeto sob seus diversos ângulos, comparar os resultados de duas ou mais técnicas de coleta de dados e de duas ou mais fontes de informação, por exemplo. (4) A validação dos relatos, comparando as falas com as observações de campo. (5) O alerta para os relatos e os fatos que contradigam as propostas e as hipóteses do investigador, tratando de problematizá-los e de apresentá-los, em lugar de ocultá-los. E (5) a fidedignidade aos vários pontos de vista, garantindo a diversidade de sentidos expressos pelos interlocutores, fugindo à idéia de verdade única.

\section{Conclusões}

Antes de terminar essas reflexões, gostaria de lembrar que muitos artefatos tecnológicos têm sido criados para a produção de análises qualitativas. Há pesquisadores que os utilizam e certamente encontram nele um importante apoio, como o demonstra a obra de Pope e Mays ${ }^{24}$.

Talvez por hábito de estar presente de forma analítica e crítica em cada uma das etapas da investigação, sinto muita dificuldade em terceirizar, para tais dispositivos, a tarefa analítica, uma vez que ela privilegia uma etapa apenas e não leva em conta o contexto intersubjetivo indissociável e filosoficamente fundamental para a pesquisa qualitativa e, portanto, para o processo de análise. 
Por isso, neste texto, toda a reflexão supõe a presença e o acompanhamento do pesquisador em cada passo do trabalho, num movimento ao mesmo tempo somativo e de superação da fase anterior. A implicação do investigador no trabalho se constitui numa perspectiva circular: "ele só conhece a realidade na medida em que a cria" 25 . Partindo dessa compreensão, considero que nem um bom técnico-analista de conteúdo pode garantir a qualidade de um texto final quando não se dá conta das condições de sua produção.

O reconhecimento de que existe uma polaridade complementar entre sujeito e objeto no processo qualitativo de construção científica leva, por sua vez, à necessidade de um esforço metodológico que garanta a objetivação, ou seja, a produção de uma análise o mais possível sistemática e aprofundada e que minimize as incursões do subjetivismo, do achismo e do espontaneísmo. Nesse sentido, sem contradizer o que falei no parágrafo anterior, é preciso valorizar as técnicas: para revisão sistemática ou narrativa da indagação inicial, tor- nando-a um objeto pensado; para elaboração de hipóteses coerentes com a pergunta e que possam guiar o trabalho; para construção dos instrumentos que devem traduzir os conceitos em itens observáveis ou em guias para conversas no campo; para elaboração de uma narrativa sobre o objeto que ao mesmo tempo leve em conta a preparação realizada cuidadosamente e a supere, trazendo novas descobertas e relevâncias; para organizar, categorizar, contextualizar e construir o relato final, fruto sempre de uma análise provisória.

O percurso analítico e sistemático, portanto, tem o sentido de tornar possível a objetivação de um tipo de conhecimento que tem como matéria prima opiniões, crenças, valores, representações, relações e ações humanas e sociais sob a perspectiva dos atores em intersubjetividade. Desta forma, a análise qualitativa de um objeto de investigação concretiza a possibilidade de construção de conhecimento e possui todos os requisitos e instrumentos para ser considerada e valorizada como um construto científico.

\section{Referências}

1. Adorno M, Horcheimer TW. Sociológica. Madrid: Editora Taurus; 1991.

2. Demo P. Introdução à metodologia científica. São Paulo: Atlas; 1988.

3. Minayo MCS. O desafio do conhecimento. $12^{\mathrm{a}}$ ed. São Paulo: Editora Hucitec; 2010.

4. Heidegger M. Heidegger. São Paulo: Editora Abril; 1980. (Coleção Os Pensadores)

5. Habermas J. Teoria da ação comunicativa. Madrid: Taurus; 1999.

6. Gadamer HG. Verdade e método. Tradução de Flávio Paulo Meurer. 3a edição. Petrópolis: Vozes; 1999.

7. Bachelard G. Essai sur la connaissance approchée. Paris: J.Vrin Editeur; 1927.

8. Minayo MCS. Los conceptos estructurantes de la investigación cualitativa. Salud colectiva [periódico na Internet]. 2010 [acessado 2011 ago 17]; 6(3):251261. Disponível em: <http://www.scielo.org.ar/ scielo.php?script $=$ sci_arttext $\&$ pid $=$ S1851-826520 $10000300002 \& \operatorname{lng}=\mathrm{es} \& \mathrm{nrm}=\mathrm{iso}>$.

9. Heidegger M. Ser e tempo. Petrópolis: Vozes; 1988.

10. Schütz A. The Phenomenology of the Social World. Translation G. Walsh and F. Lehnert. Evanston: Northwestern University Press; 1967.

11. Merleau-Ponty M. Fenomenologia da percepção. Tradução de Reginaldo de Pietro. São Paulo: Freitas Bastos; 2006.

12. Habermas J. Dialética e Hermenêutica - para a crítica da hermenêutica de Gadamer. Porto Alegre: L\&PM; 1987.

13. Pascal B. Pensamentos. São Paulo: Abril Cultural; 1979.
14. Malinowski B. Os Argonautas do Pacífico Ocidental. São Paulo: Abril Cultural; 1978. (Coleção Os Pensadores)

15. Lévy-Strauss C. Introdution à l'ouevre de Marcel Mauss. In: Mauss M. Sociologie et anthropologie. Paris: Presses Universitaire de France; 1950. p. 220.

16. Bertaux D. Cahiers Internationaux de Sociologie. Paris: Presses Universitaires de France; 1980.

17. Canguilhem G. O normal e o patológico. Rio de Janeiro: Editora Forense Universitária; 1978.

18. Dilthey W. Introducción a las Ciencias del Espíritu. Madrid: Ed. Revista del Ocidente; 1956.

19. Schleiermacher FI. Hermenêutica: arte e técnica da interpretação. 2aaed. Petrópolis: Vozes; 2000.

20. Marx K. Para a crítica da economia política. São Paulo: Nova Cultural; 1991. (Coleção Os Pensadores)

21. Geertz C. Nova luz sobre a antropologia. Rio de Janeiro: Jorge Zahar Editor; 2001

22. Popper KR. Lógica das ciências sociais. Brasília: Universidade de Brasília; 1978.

23. Denzin N, editor. The research act in sociology: a theoretical introduction to sociological method. New York: McGraw-Hill; 1970.

24. Pope C, Mays N. Qualitative Research in health care. Massassuchets: Blackwell Publishing Ltd; 2006.

25. Kosik K. Dialética do concreto. Rio de Janeiro: Paz e Terra; 1969.

Apresentado em 01/09/2011

Aprovado em 12/10/2011

Versão final apresentada em 16/10/2011 